\title{
Differences in the early stage gene expression profiles of lung adenocarcinoma and lung squamous cell carcinoma
}

\author{
NITIN VENUGOPAL ${ }^{1 *}$, JUSTIN YEH $^{1 *}$, SAI KARTHIK KODEBOYINA ${ }^{1}$, TAE JIN LEE ${ }^{1}$, \\ SHRUTI SHARMA ${ }^{1,2}$, NIKHIL PATEL ${ }^{3}$ and ASHOK SHARMA ${ }^{1,4}$ \\ ${ }^{1}$ Center for Biotechnology and Genomic Medicine; Departments of ${ }^{2}$ Ophthalmology, ${ }^{3}$ Pathology and \\ ${ }^{4}$ Population Health Sciences, Medical College of Georgia, Augusta University, Augusta, GA 30912, USA
}

Received February 27, 2019; Accepted August 6, 2019

DOI: $10.3892 / 01.2019 .11013$

\begin{abstract}
The discovery of lung carcinoma subtype-specific gene expression changes has the potential to elucidate the molecular differences and provide personalized therapeutic targets for these pathologies. The aim of the present study was to characterize the genetic profiles of the early stages (IA/IB) of two non-small cell lung cancer subtypes, adenocarcinoma (AD) and squamous cell carcinoma (SC). RNA-Seq gene expression data from The Cancer Genome Atlas was analyzed to compare the gene expression differences between $\mathrm{AD}$ and $\mathrm{SC}$. The gene sets specific to each subtype were further analyzed to identify the enriched Gene Ontology terms, Kyoto Encyclopedia of Genes and Genomes pathways and biological functions. The results demonstrated that a unique set of genes (145 upregulated and 27 downregulated) was altered in AD, but not in SC; another set of genes (146 upregulated and 103 downregulated) was significantly altered in SC, but not in AD. Genes highly upregulated specifically in AD included albumin (1,732-fold), protein lin-28 homolog $\mathrm{A}$, which is a positive regulator of cyclin-dependent kinase 2 (150-fold) and gastric lipase (81-fold). Genes highly upregulated specifically in SC included amelotin (618-fold), alcohol dehydrogenase 7 (57-fold), aclerosteosis (55-fold) and claudin-22 (54-fold). Several cancer/testis antigen family genes were notably upregulated in SC, but not in AD, whereas mucins were upregulated only in AD. Functional pathway analysis demonstrated that the dysregulation of genes associated with retinoid $\mathrm{X}$ receptors was common in AD and SC, genes associated with 'lipid metabolism' and 'drug metabolism' were dysregulated only in SC, whereas genes associated with 'molecular transport'
\end{abstract}

Correspondence to: Dr Ashok Sharma, Center for Biotechnology and Genomic Medicine, Medical College of Georgia, Augusta University, 1120 15th Street, CA4094, Augusta, GA 30912, USA

E-mail: assharma@augusta.edu

${ }^{*}$ Contributed equally

Key words: non-small cell lung cancer, lung adenocarcinoma, lung squamous cell carcinoma, The Cancer Genome Atlas and 'cellular growth and proliferation' were significantly enriched in AD specifically. These results reveal fundamental differences in the gene expression profiles of early-stage AD and SC. In addition, the present study identified molecular pathways that are uniquely associated with the pathogenesis of these subtypes.

\section{Introduction}

Non-small cell lung cancers (NSCLC), which are classified into adenocarcinomas (AD) and squamous cell carcinomas (SC), account for $\sim 85 \%$ of primary lung cancer cases and are responsible for $\sim 25 \%$ of cancer deaths in the United States (1-4). Previous studies have identified key differences between these histological subtypes at the molecular level, and have demonstrated the potential of these differences as diagnostic biomarkers and predictors of overall survival (5-7). For example, the mammary serine protease inhibitor maspin has been demonstrated to be highly expressed in SC, but not in $\mathrm{AD}$ (5). In addition, thyroid transcription factor 1 has been effectively used as an immunohistochemical marker to differentiate AD from SC (7). Several studies have examined gene expression profiles in lung cancer, including studies differentiating AD and SC (8-12). Shi et al (9) identified 2,961 microRNA sequences that may regulate differentially expressed genes (DEGs) in both NSCLC and small cell lung cancer across all clinical stages. Lu et al (10) studied DEGs in NSCLC subtypes across all stages, identifying a set of upregulated and downregulated genes in AD and SC but had a limited sample size. A total of 1,127 DEGs in NSCLC were identified by Grigoroiu et al (12), however they focused specially on stage IIIA disease and did not differentiate between AD and SC. Thus, the number of studies focusing on gene expression profiles specifically at the early stages (IA and IB) of NSCLC is low. Therefore, the present study aimed to provide a unique perspective by identifying gene expression changes specific to the early stages of AD and SC. Gene expression profiling of early-stage lung cancer may have great value in identifying potential molecular targets for the early detection and treatment of NSCLC.

The 5-year survival rate of patients with NSCLC who start treatment during stage IA of the disease is $~ 92 \%$; however, the 5 -year survival rate is $60 \%$ for stage IIA, $36 \%$ for stage IIIA 
and $<10 \%$ for stage IVA (13). Thus, diagnosis and treatment at the early stages are crucial for improving the survival rates of patients with NSCLC. Genomic profiles of early-stage NSCLC may be particularly advantageous with the advent of next generation sequencing panels that allow rapid identification of personalized therapies for cancer by analyzing genetic variants in tissue biopsies (14). This technology has been demonstrated to provide clinical benefits in NSCLC and is routinely used to identify common mutations in lung cancer, such as KRAS and epidermal growth factor receptor $(15,16)$. The identification of novel genes and pathways uniquely expressed in early stages of AD and SC may provide more specific elements for evolving personalized therapies, such as specific drug targets or as a component of a panel for a prognostic screening test.

The aim of the present study was to identify the unique signatures of $\mathrm{SC}$ and $\mathrm{AD}$, by comparing the gene expression levels in each carcinoma to fully characterize the genetic profiles of each subtype. These unique gene sets may improve our understanding of the molecular basis of each NSCLC subtype and may provide more specific targets for personalized therapy.

\section{Materials and methods}

The cancer genome atlas (TCGA) datasets. TCGA (https://www.cancer.gov/about-nci/organization/ccg/research/ structural-genomics/tcga) is a landmark dataset, which comprises the molecular characterization of over 20,000 samples spanning 33 different cancer types, publicly available to the research community. TCGA gene expression RNA-Seq data was downloaded from Xenabrowser (http://xenabrowser.net). Data for the early stages (IA and IB) (AJCC 7th Edition TNM Staging System; https://cancerstaging.org) of $\mathrm{AD}$ and $\mathrm{SC}$, as well as those for adjacent normal tissues, were selected. Gene expression levels were compared between the cancer and normal lung tissue samples to identify DEGs in each subtype.

Statistical analysis. All statistical analyses were performed using the $\mathrm{R}$ language and environment for statistical computing ( $\mathrm{R}$ version 3.2.2; R Foundation for Statistical Computing; www.r-project.org). The edgeR package (https://bioconductor. org/packages/release/bioc/html/edgeR.html) was used to perform differential expression analysis of all genes with count per million $(\mathrm{CPM})>1$ in at $\geq 2$ samples, and two separate differential gene expression analyses were performed for each cancer type (AD and SC). To identify DEGs in each subtype, the gene expression data for the early stages of each carcinoma were compared with those for the adjacent normal tissues. The Benjamini and Hochberg's method (17) was used to control the false discovery rate. The level of change in gene expression was expressed as the mean fold-change (FC) between the cancerous and adjacent normal tissues. To identify highly significantly upregulated genes, a filter of $|F C| \geq$ 4 and adjusted $\mathrm{P}<0.001$ was used. The FCs of downregulated genes were transformed with a negative reciprocal, as the negative reciprocal FC of a downregulated gene has a negative sign, but retains the fold difference information, which is similar to $\log \mathrm{FC}$. For example, FC of 0.5 is the same as 2-fold downregulation (-2 fold-change). To identify the genes uniquely differentially expressed in either subtype, DEGs were assigned to the following categories: i) Genes upregulated in $\mathrm{AD}\left(\mathrm{FC}_{\mathrm{AD}}>4 ; \mathrm{P}_{\mathrm{AD}}<0.001\right)$, but not in $\mathrm{SC}$; ii) genes upregulated in $\mathrm{SC}\left(\mathrm{FC}_{\mathrm{SC}}>4 ; \mathrm{P}_{\mathrm{SC}}<0.001\right)$, but not in $\mathrm{AD}$ (Table I); iii) genes downregulated in $\mathrm{AD}\left(\mathrm{FC}_{\mathrm{AD}}<-4 ; \mathrm{P}_{\mathrm{AD}}<0.001\right)$, but not in $\mathrm{SC}$; and iv) genes downregulated in $\mathrm{SC}\left(\mathrm{FC}_{\mathrm{SC}}<-4 ; \mathrm{P}_{\mathrm{AD}}<0.001\right)$, but not in AD (Table II).

Functional analysis of DEGs. An Ingenuity Pathway Analysis (IPA) software tool (https://www.qiagenbioinformatics. com/products/ingenuity-pathway-analysis) was used to determine the underlying mechanisms, functions, pathways and associations between the gene sets identified during DEG analysis. Molecular and cellular functions and canonical pathways were identified using IPA to distinguish the complex biology underlying the pathogenesis of the two lung cancer subtypes. Upstream regulator analysis using IPA was performed to discover the upstream transcriptional factors regulating changes in the expression of the identified genes. The analysis is based on the expected effects between transcriptional regulators and their targets stored in the Ingenuity database. The analysis provides a $\mathrm{P}$-value and an activation $\mathrm{z}$-score based on the number of known targets present in the DEGs for each transcriptional regulator. Overall, this analysis is part of IPA core analysis examining the mechanisms, functions and pathways associated with a given set of genes.

\section{Results}

Identification of DEGs. RNA-Seq gene expression data from TCGA were analyzed to compare the gene expression changes in the early stages of two NSCLC subtypes. A total of 145 genes were upregulated specifically in AD, and 146 genes were upregulated specifically in SC. Among the downregulated genes, 27 were downregulated specifically in AD, whereas 103 were downregulated specifically in SC. Venn diagrams representing the number of upregulated and downregulated genes in the two NSCLC subtypes are presented in Fig. 1A and B. A heat map was constructed to identify the expression patterns of these unique gene sets in each subtype (Fig. 1C). The patients were stratified by smoking status to determine whether the DEGs were associated with smoking; the results demonstrated that early-stage differences unique to each subtype were not associated with smoking (data not shown).

Genes differentially expressed in $A D$. A total of 145 genes were highly upregulated specifically in $\mathrm{AD}\left(\mathrm{FC}_{\mathrm{AD}}>4\right.$; $\mathrm{P}_{\mathrm{AD}}<0.001$ ) with no significant upregulation in $\mathrm{SC}$. The genes with the highest FC uniquely upregulated in each subtype are presented in Table I. In addition, 27 genes were significantly downregulated specifically in $\mathrm{AD}\left(\mathrm{FC}_{\mathrm{AD}}<-4 ; \mathrm{P}_{\mathrm{AD}}<0.001\right)$ with no significant downregulation in SC (Table II). Highly upregulated genes specific to AD included albumin ( $A L B ; \mathrm{AD}$, $\mathrm{FC}=1,732.04 ; \mathrm{SC}, \mathrm{FC}=-1.48$ ), protein lin-28 homolog $\mathrm{A}$ (LIN28A; $\mathrm{AD}, \mathrm{FC}=150.39 ; \mathrm{SC}, \mathrm{FC}=1.25)$, gastric lipase (LIPF; AD, FC=81.24; SC, FC=2.69), transmembrane $4 \mathrm{~L}$ six family member 4 (TM4SF4; AD, FC=68.74; $\mathrm{SC}, \mathrm{FC}=-2.73$ ) 
Table I. Upregulated genes in AD and SC.

A, Genes upregulated specifically in AD

\begin{tabular}{|c|c|c|c|c|c|}
\hline Gene & Gene name & $\mathrm{AD} F C$ & AD P-value & $\mathrm{SC} \mathrm{FC}$ & SC P-value \\
\hline ALB & Albumin & $1,732.04$ & $8.37 \times 10^{-21 a}$ & -1.48 & 0.205 \\
\hline LIN28A & Protein lin-28 homolog A & 150.39 & $1.18 \times 10^{-8 a}$ & 1.25 & 0.482 \\
\hline LIPF & Lipase, gastric & 81.24 & $5.48 \times 10^{-7 a}$ & 2.69 & 0.057 \\
\hline TM4SF4 & Transmembrane 41 six family member 4 & 68.74 & $4.11 \times 10^{-18 a}$ & -2.73 & $<0.001^{\mathrm{a}}$ \\
\hline AGXT2L1 & Alanine-glyoxylate aminotransferase 2-like 1 & 66.16 & $4.11 \times 10^{-11 a}$ & -1.89 & 0.087 \\
\hline ACMSD & Aminocarboxymuconate semialdehyde decarboxylase & 50.76 & $1.05 \times 10^{-17 a}$ & 1.60 & 0.314 \\
\hline PLUNC & Palate, lung and nasal epithelium carcinoma associated & 38.01 & $4.59 \times 10^{-13 a}$ & 1.57 & 0.299 \\
\hline CDHR2 & Cadherin-related family member 2 & 34.47 & $9.39 \times 10^{-11 a}$ & 1.49 & 0.135 \\
\hline CNGA3 & Cyclic nucleotide gated channel $\alpha 3$ & 33.38 & $3.92 \times 10^{-21 a}$ & -1.63 & 0.020 \\
\hline SLC14A2 & Solute carrier family 14 (urea transporter), member 2 & 32.14 & $8.58 \times 10^{-14 a}$ & -1.02 & 0.894 \\
\hline TMEM229A & Transmembrane protein $229 \mathrm{~A}$ & 26.86 & $1.86 \times 10^{-12 a}$ & -1.47 & 0.125 \\
\hline GLTPD2 & Glycolipid transfer protein domain containing 2 . & 25.59 & $4.10 \times 10^{-13 a}$ & 1.23 & 0.671 \\
\hline COL25A1 & Collagen, type xxv, $\alpha 1$ & 24.22 & $2.69 \times 10^{-15 a}$ & 1.08 & 0.797 \\
\hline GKN1 & Gastrokine 1 & 23.84 & $4.54 \times 10^{-5 a}$ & -2.85 & $<0.001^{\mathrm{a}}$ \\
\hline NPTX1 & Neuronal pentraxin I & 21.88 & $3.19 \times 10^{-18 a}$ & 1.17 & 0.448 \\
\hline FAM177B & Family with sequence similarity 177 , member b & 20.74 & $1.13 \times 10^{-21 a}$ & 1.09 & 0.797 \\
\hline LOC643763 & Hypothetical protein loc643763 & 19.57 & $6.23 \times 10^{-12 \mathrm{a}}$ & 1.92 & 0.077 \\
\hline LOC 145837 & Hypothetical protein loc 145837 & 19.20 & $1.96 \times 10^{-20 \mathrm{a}}$ & 1.47 & 0.128 \\
\hline $\mathrm{ZP} 2$ & Zona pellucida glycoprotein 2 (sperm receptor) & 18.62 & $8.39 \times 10^{-6 a}$ & -2.63 & $<0.001^{\mathrm{a}}$ \\
\hline TFPI2 & Tissue factor pathway inhibitor 2 & 17.86 & $2.40 \times 10^{-17 a}$ & -1.01 & 0.930 \\
\hline LGALS4 & Lectin, galactoside-binding, soluble, 4 (galectin 4) & 17.76 & $6.23 \times 10^{-12 a}$ & -2.71 & $<0.001^{\mathrm{a}}$ \\
\hline KNG1 & Kininogen 1 & 17.56 & $1.99 \times 10^{-7 a}$ & 1.83 & 0.097 \\
\hline TTR & Transthyretin (prealbumin, amyloidosis type I) & 17.14 & $3.31 \times 10^{-7 a}$ & 2.86 & 0.054 \\
\hline PHGR1 & Proline, histidine, and glysine-rich protein 1 & 17.13 & $4.30 \times 10^{-6 a}$ & 2.38 & 0.076 \\
\hline MUC21 & Mucin 21, cell surfaceassociated & 14.87 & $1.96 \times 10^{-20 a}$ & -2.79 & $<0.001^{\mathrm{a}}$ \\
\hline MUC5B & Mucin $5 b$, oligomeric mucus/gel-forming & 14.01 & $4.66 \times 10^{-14 a}$ & -1.13 & 0.640 \\
\hline FGA & Fibrinogen $\alpha$ chain & 12.68 & $2.45 \times 10^{-10 a}$ & -1.92 & 0.020 \\
\hline UPK3A & Uroplakin $3 \mathrm{a}$ & 12.53 & $2.47 \times 10^{-20 \mathrm{a}}$ & 1.28 & 0.239 \\
\hline SLC1A7 & $\begin{array}{l}\text { Solute carrier family } 1 \text { (glutamate transporter), } \\
\text { member } 7\end{array}$ & 12.38 & $1.11 \times 10^{-14 a}$ & -3.80 & $<0.001^{\mathrm{a}}$ \\
\hline RGS7 & Regulator of g-protein signaling 7 & 12.38 & $6.30 \times 10^{-12 a}$ & 1.56 & 0.208 \\
\hline
\end{tabular}

B, Genes upregulated specifically in SC

\begin{tabular}{|c|c|c|c|c|c|}
\hline Gene & Gene name & $\mathrm{AD} \mathrm{FC}$ & AD P-value & $\mathrm{SC} \mathrm{FC}$ & SC P-value \\
\hline AMTN & Amelotin & 1.70 & 0.137 & 618.16 & $4.66 \times 10^{-25 a}$ \\
\hline ADH7 & $\begin{array}{l}\text { Alcohol dehydrogenase } 7 \text { (class iv), mu or } \\
\text { sigma polypeptide }\end{array}$ & 1.52 & 0.277 & 57.12 & $3.30 \times 10^{-23 a}$ \\
\hline SOST & Sclerostin & -1.81 & 0.027 & 54.92 & $3.90 \times 10^{-18 a}$ \\
\hline CLDN22 & Claudin 22 & 2.46 & 0.059 & 54.24 & $5.77 \times 10^{-6 a}$ \\
\hline SOX10 & SRY (sex determining region y)-box 10 & 1.76 & 0.050 & 39.80 & $1.92 \times 10^{-10 a}$ \\
\hline C12orf54 & Chromosome 12 open reading frame 54 & 1.72 & 0.053 & 39.51 & $2.34 \times 10^{-34 a}$ \\
\hline GPR149 & G protein-coupled receptor 149 & 2.42 & 0.116 & 38.62 & $7.30 \times 10^{-13 a}$ \\
\hline SCGN & Secretagogin, ef-hand calcium binding protein & 1.96 & 0.172 & 37.66 & $2.92 \times 10^{-5 a}$ \\
\hline SLC35D3 & Solute carrier family 35 , member $\mathrm{d} 3$ & -1.20 & 0.456 & 37.43 & $3.85 \times 10^{-13 a}$ \\
\hline CT45A3 & Cancer/testis antigen family 45 , member a 3 & 3.01 & 0.151 & 35.61 & $2.05 \times 10^{-5 a}$ \\
\hline ADAM23 & Adam metallopeptidase domain 23 & 1.01 & 1.000 & 34.46 & $1.71 \times 10^{-29 a}$ \\
\hline ST8SIA3 & St8 $\alpha$-n-acetyl-neuraminide $\alpha$-2,8-sialyltransferase 3 & 3.17 & 0.059 & 33.69 & $7.23 \times 10^{-5 a}$ \\
\hline HOXD10 & Homeobox d10 & 1.53 & 0.120 & 32.56 & $3.08 \times 10^{-36 a}$ \\
\hline
\end{tabular}


Table I. Continued.

\begin{tabular}{llcccc}
\hline Gene & \multicolumn{1}{c}{ Gene name } & AD FC & AD P-value & SC FC & SC P-value \\
\hline LMO1 & Lim domain only 1 (rhombotin 1) & 1.59 & 0.072 & 31.08 & $1.71 \times 10^{-24 \mathrm{a}}$ \\
ODZ2 & Odz, odd oz/ten-m homolog 2 & 1.00 & 0.972 & 30.69 & $2.36 \times 10^{-30 \mathrm{a}}$ \\
CLDN19 & Claudin 19 & -1.62 & 0.070 & 30.28 & $1.95 \times 10^{-10 \mathrm{a}}$ \\
FOXN1 & Forkhead box n1 & 1.19 & 0.339 & 29.93 & $6.61 \times 10^{-35 \mathrm{a}}$ \\
APOA1 & Apolipoprotein a-i & 1.81 & 0.064 & 29.75 & $8.79 \times 10^{-9} \mathrm{a}$ \\
HS3ST4 & Heparan sulfate (glucosamine) 3-o-sulfotransferase 4 & 1.74 & 0.097 & 29.69 & $3.25 \times 10^{-11 \mathrm{a}}$ \\
PAX1 & Paired box 1 & 1.63 & 0.225 & 28.10 & $7.10 \times 10^{-11 \mathrm{a}}$ \\
OLFM3 & Olfactomedin 3 & 2.73 & 0.050 & 26.58 & $2.93 \times 10^{-9} \mathrm{a}$ \\
FAM181B & Family with sequence similarity 181, member b & 1.11 & 0.668 & 25.19 & $1.25 \times 10^{-39 a}$ \\
CRNN & Cornulin & 2.06 & 0.129 & 24.94 & $1.37 \times 10^{-8 \mathrm{a}}$ \\
TP53AIP1 & Tumor protein p53 regulated apoptosis inducing & -1.02 & 0.916 & 23.03 & $8.00 \times 10^{-25 \mathrm{a}}$ \\
& protein 1 & & & & \\
TCHHL1 & Trichohyalin-like 1 & 2.34 & 0.242 & 22.08 & $1.38 \times 10^{-17 \mathrm{a}}$ \\
SERPINB2 & Serpin peptidase inhibitor, clade b (ovalbumin) & -1.06 & 0.802 & 21.55 & $8.28 \times 10^{-21 \mathrm{a}}$ \\
& member 2 & & & & \\
QRFPR & Pyroglutamylated rfamide peptide receptor & -2.30 & 0.003 & 21.09 & $1.94 \times 10^{-10 \mathrm{a}}$ \\
TGM3 & Transglutaminase 3 & -1.59 & 0.039 & 20.25 & $2.65 \times 10^{-13 \mathrm{a}}$ \\
CT45A1 & Cancer/testis antigen family 45, member a1 & 1.74 & 0.302 & 20.10 & $5.63 \times 10^{-7 \mathrm{a}}$ \\
CT45A4 & Cancer/testis antigen family 45, member a4 & 3.55 & 0.079 & 19.29 & $1.5 \times 10^{-4 a}$ \\
\hline
\end{tabular}

${ }^{\mathrm{a}} \mathrm{P}<0.001$. AD, lung adenocarcinoma; $\mathrm{SC}$, squamous cell carcinoma; $\mathrm{FC}$, fold change.

and alanine-glyoxylate aminotransferase 2-like 1 (AGXT2L1; $\mathrm{AD}, \mathrm{FC}=66.16$; $\mathrm{SC}, \mathrm{FC}=-1.89)$. The LIN28A gene is a cell cycle regulator, the role of which has been identified in a number of human cancers $(18,19)$, but not in NSCLC. AD also demonstrated $\sim 15$-fold upregulation in the mucin (MUC) family of genes, which may be associated with the secretory nature of the tumor. The top downregulated genes specific to $\mathrm{AD}$ included adenylate cyclase $8(\mathrm{AD}, \mathrm{FC}=-11.65 ; \mathrm{SC}$, $\mathrm{FC}=2.13$ ), sclerostin domain-containing 1 (SOSTDC1; AD, $\mathrm{FC}=-10.96$; $\mathrm{SC}, \mathrm{FC}=-1.01)$, solute carrier organic anion transporter family member 1A2 (AD, FC=-10.09; SC, FC=-1.29), cholinergic receptor nicotinic $\alpha 2$ subunit (AD, FC=-10.08; $\mathrm{SC}$, $\mathrm{FC}=-1.43)$ and odontogenic ameloblast-associated (ODAM; $\mathrm{AD}, \mathrm{FC}=-9.92 ; \mathrm{SC}, \mathrm{FC}=3.22$ ).

Genes differentially expressed in SC. A total of 146 genes were highly upregulated in $\mathrm{SC}\left(\mathrm{FC}_{\mathrm{SC}}>4 ; \mathrm{P}_{\mathrm{SC}}<0.001\right)$ with no significant upregulation in $\mathrm{AD}$ (Table I). In addition, 103 genes were significantly downregulated $\left(\mathrm{FC}_{\mathrm{SC}}<-4 ; \mathrm{P}_{\mathrm{SC}}<0.001\right)$ in $\mathrm{SC}$ with no downregulation in $\mathrm{AD}$ (Table II). The top upregulated genes unique to $\mathrm{SC}$ were amelotin $(A M T N$; $\mathrm{SC}, \mathrm{FC}=618.16 ; \mathrm{AD}, \mathrm{FC}=1.70)$, alcohol dehydrogenase 7 (ADH7; SC, FC=57.12; AD, $\mathrm{FC}=1.52$ ), sclerostin (SOST; $\mathrm{SC}, \mathrm{FC}=54.92 ; \mathrm{AD}, \mathrm{FC}=-1.81)$, claudin 22 (CLDN22; $\mathrm{SC}$, $\mathrm{FC}=54.24$; $\mathrm{AD}, \mathrm{FC}=2.46)$ and SRY-box 10 (SC, FC=39.80; $\mathrm{AD}, \mathrm{FC}=1.76$ ). In addition, early-stage $\mathrm{SC}$ exhibited unique upregulation of several members of the cancer/testis antigen (CTA) family of genes. The top downregulated genes specific to $\mathrm{SC}$ were myosin heavy chain 1 ( $\mathrm{SC}, \mathrm{FC}=-16.35$; $\mathrm{AD}$, $\mathrm{FC}=-1.33)$, progastricsin $(\mathrm{SC}, \mathrm{FC}=-16.06 ; \mathrm{AD}, \mathrm{FC}=3.89)$, chitinase acidic (SC, FC-15.74; AD, FC=1.25), surfactant-associated 2 (SC, FC=-14.51; $\mathrm{AD}, \mathrm{FC}=1.15)$ and apolipoprotein $\mathrm{H}$ $(\mathrm{SC}, \mathrm{FC}=-13.95 ; \mathrm{AD}, \mathrm{FC}=1.82)$.

Analysis of molecular pathways in AD. The IPA tool was used to generate an interaction network for genes specifically differentially regulated in AD and SC, based on known interactions (Fig. 2). The genes uniquely dysregulated in AD were enriched in a number of molecular and cellular functions, including 'molecular transport', 'cell-to-cell signaling and interaction', 'amino acid metabolism' and 'cellular growth and proliferation'. A number of the dysregulated genes specific to AD were also involved in the canonical farnesoid $\mathrm{X}$ receptor $(\mathrm{NR} 1 \mathrm{H} 4)$ /retinoid $\mathrm{X}$ receptor $(\mathrm{RXR})$ activation and liver $\mathrm{X}$ receptor (LXR)/RXR activation pathways. The roles of these regulators in NSCLCs have not been previously reported. A number of upstream regulators of these genes were identified, including hepatocyte nuclear factor $4 \alpha(H N F 4 A)$, which regulated 26 genes, $H N F 1 A$, which regulates 22 genes, transcription activator BRG1 (SMARCA4), which regulates 14 genes, and Forkhead Box A2 (FOXA2), which regulated 10 genes (Table III). The HNF family of genes and FOXA2 have been independently associated with AD as positive and negative regulators of growth, respectively $(20,21)$.

Analysis of molecular pathways in SC. The genes unique to early-stage SC were enriched in 'xenobiotic metabolism', 'lipid metabolism', 'vitamin and mineral metabolism', 'drug metabolism' and 'free radical scavenging'. These results suggested that impaired lipid metabolism is specific to SC. 
Table II. Downregulated genes in AD and SC.

A, Genes downregulated specifically in AD

\begin{tabular}{|c|c|c|c|c|c|}
\hline Gene & Gene name & $\mathrm{AD} \mathrm{FC}$ & AD P-value & SC FC & SC P-value \\
\hline ADCY8 & Adenylate cyclase 8 (brain) & -11.65 & $8.60 \times 10^{-24 a}$ & 2.13 & 0.073 \\
\hline SOSTDC1 & Sclerostin domain containing 1 & -10.96 & $2.73 \times 10^{-39 a}$ & -1.01 & 0.937 \\
\hline SLCO1A2 & $\begin{array}{l}\text { Solute carrier organic anion transporter } \\
\text { family, member }\end{array}$ & -10.09 & $1.71 \times 10^{-26 a}$ & -1.29 & 0.146 \\
\hline CHRNA2 & Cholinergic receptor, nicotinic, $\alpha 2$ (neuronal) & -10.08 & $1.20 \times 10^{-43 a}$ & -1.43 & 0.292 \\
\hline ODAM & Odontogenic, ameloblast associated & -9.92 & $2.10 \times 10^{-33 a}$ & 3.22 & 0.009 \\
\hline KRT79 & Keratin 79 & -8.53 & $3.65 \times 10^{-33 a}$ & -1.06 & 0.788 \\
\hline SYN2 & Synapsin ii & -7.58 & $5.50 \times 10^{-37 a}$ & -1.05 & 0.790 \\
\hline S100A12 & S100 calcium binding protein a 12 & -6.92 & $5.97 \times 10^{-45 a}$ & -1.26 & 0.310 \\
\hline TGM1 & Transglutaminase 1 & -6.87 & $1.19 \times 10^{-78 a}$ & 2.44 & $<0.001^{\mathrm{a}}$ \\
\hline ANXA8L2 & Annexin a8-like 2 & -6.84 & $2.81 \times 10^{-29 a}$ & 1.78 & $<0.001^{\mathrm{a}}$ \\
\hline SLITRK2 & Slit and ntrk-like family, member 2 & -6.63 & $3.63 \times 10^{-36 a}$ & -1.09 & 0.730 \\
\hline DCC & Deleted in colorectal carcinoma & -6.26 & $1.78 \times 10^{-40 \mathrm{a}}$ & 1.10 & 0.773 \\
\hline FGFBP2 & Fibroblast growth factor binding protein 2 & -5.78 & $1.31 \times 10^{-24 a}$ & 5.56 & $<0.001^{\mathrm{a}}$ \\
\hline VIT & Vitrin & -5.56 & $3.27 \times 10^{-28 a}$ & 5.59 & $<0.001^{\mathrm{a}}$ \\
\hline LPPR5 & $\begin{array}{l}\text { Lipid phosphate phosphatase-related } \\
\text { protein type } 5\end{array}$ & -5.55 & $9.97 \times 10^{-19 a}$ & -1.34 & 0.311 \\
\hline VWC2 & Von willebrand factor c domain containing 2 & -4.62 & $4.26 \times 10^{-31 a}$ & 2.15 & 0.008 \\
\hline NOS 1 & Nitric oxide synthase 1 (neuronal) & -4.50 & $1.75 \times 10^{-11 \mathrm{a}}$ & 1.11 & 0.769 \\
\hline HSPB3 & Heat shock $27 \mathrm{kda}$ protein 3 & -4.47 & $3.32 \times 10^{-26 a}$ & 1.73 & 0.021 \\
\hline SEMA6D & Semaphoring 6D & -4.28 & $1.70 \times 10^{-33 a}$ & -1.14 & 0.404 \\
\hline NTRK2 & Neurotrophic tyrosine kinase, receptor, type 2 & -4.21 & $1.10 \times 10^{-18 a}$ & 9.48 & $<0.001^{\mathrm{a}}$ \\
\hline SLC27A6 & $\begin{array}{l}\text { Solute carrier family } 27 \text { (fatty acid } \\
\text { transporter), member } 6\end{array}$ & -4.12 & $4.37 \times 10^{-10 a}$ & -1.34 & 0.297 \\
\hline CHRNA4 & Cholinergic receptor, nicotinic, $\alpha 4$ & -4.11 & $5.82 \times 10^{-16 a}$ & 2.21 & 0.013 \\
\hline EDN3 & Endothelin 3 & -4.09 & $3.04 \times 10^{-9 \mathrm{a}}$ & 3.96 & 0.014 \\
\hline NDRG4 & Ndrg family member 4 & -4.08 & $6.96 \times 10^{-34 a}$ & 1.73 & 0.002 \\
\hline KRT4 & Keratin 4 & -4.03 & $2.93 \times 10^{-11 a}$ & 2.55 & 0.006 \\
\hline FEZ1 & $\begin{array}{l}\text { Fasciculation and elongation protein } \\
\text { zeta } 1 \text { (zygin i) }\end{array}$ & -4.02 & $3.18 \times 10^{-77 a}$ & -1.19 & 0.141 \\
\hline ANXA8 & Annexin a8 & -4.01 & $1.57 \times 10^{-12 \mathrm{a}}$ & 3.94 & $<0.001^{\mathrm{a}}$ \\
\hline
\end{tabular}

B, Genes downregulated specifically in SC

\begin{tabular}{|c|c|c|c|c|c|}
\hline Gene & Gene name & $\mathrm{AD} \mathrm{FC}$ & AD P-value & $\mathrm{SC} \mathrm{FC}$ & SC P-value \\
\hline MYH1 & Myosin, heavy chain 1 , skeletal muscle, adult & -1.33 & 0.336 & -16.35 & $8.37 \times 10^{-21 a}$ \\
\hline PGC & Progastricsin (pepsinogen c) & 3.89 & $<0.001^{\mathrm{a}}$ & -16.06 & $1.18 \times 10^{-8 \mathrm{a}}$ \\
\hline CHIA & Chitinase, acidic & 1.25 & 0.420 & -15.74 & $5.48 \times 10^{-7 a}$ \\
\hline SFTA2 & Surfactant associated 2 & 1.15 & 0.361 & -14.51 & $4.11 \times 10^{-18 a}$ \\
\hline $\mathrm{APOH}$ & Apolipoprotein h ( $\beta$-2-glycoprotein i) & 1.82 & 0.035 & -13.95 & $4.11 \times 10^{-11 \mathrm{a}}$ \\
\hline CAPN9 & Calpain 9 & -1.22 & 0.316 & -12.42 & $1.05 \times 10^{-17 \mathrm{a}}$ \\
\hline DPCR1 & Diffuse panbronchiolitis critical region 1 & 4.44 & $<0.001^{\mathrm{a}}$ & -12.26 & $4.59 \times 10^{-13 a}$ \\
\hline FOLR1 & Folate receptor 1 (adult) & -1.33 & 0.076 & -11.98 & $9.39 \times 10^{-11 a}$ \\
\hline SFTA3 & Surfactant-associated 3 & -1.20 & 0.184 & -11.69 & $3.92 \times 10^{-21 \mathrm{a}}$ \\
\hline C16orf89 & Chromosome 16 open reading frame 89 & 1.19 & 0.394 & -11.54 & $8.58 \times 10^{-14 a}$ \\
\hline HNF1B & Hnf1 homeobox b & 1.23 & 0.114 & -11.46 & $1.86 \times 10^{-12 \mathrm{a}}$ \\
\hline SLC10A2 & Solute carrier family 10 member 2 & 1.95 & 0.158 & -10.75 & $4.10 \times 10^{-13 a}$ \\
\hline NAPSA & Napsin a aspartic peptidase & -1.15 & 0.382 & -10.39 & $2.69 \times 10^{-15 a}$ \\
\hline CYP2B7P1 & Cytochrome p 450 , family 2 , subfamily b, & 1.23 & 0.316 & -9.97 & $4.54 \times 10^{-5 a}$ \\
\hline
\end{tabular}


Table II. Continued.

\begin{tabular}{|c|c|c|c|c|c|}
\hline Gene & Gene name & AD FC & AD P-value & $\mathrm{SC} \mathrm{FC}$ & SC P-value \\
\hline MIA2 & Melanoma inhibitory activity 2 & -1.05 & 0.783 & -9.17 & $3.19 \times 10^{-18 a}$ \\
\hline CCL14.CCL15 & C-C motif chemokine 14 & -1.91 & 0.053 & -9.13 & $1.13 \times 10^{-21 \mathrm{a}}$ \\
\hline C4BPA & Complement component 4 binding protein, $\alpha$ & -1.38 & 0.075 & -8.55 & $6.23 \times 10^{-12 a}$ \\
\hline TDRD10 & Tudor domain containing 10 & -1.01 & 0.931 & -8.50 & $1.96 \times 10^{-20 a}$ \\
\hline AQP7 & Aquaporin 7 & 2.16 & $<0.001^{\mathrm{a}}$ & -8.20 & $8.39 \times 10^{-6 a}$ \\
\hline FMO5 & Flavin containing monooxygenase 5 & 1.54 & 0.008 & -7.99 & $2.40 \times 10^{-17 a}$ \\
\hline NKX2.1 & Homeobox protein Nkx-2.1 & 1.26 & 0.067 & -7.72 & $6.23 \times 10^{-12 a}$ \\
\hline SLC26A9 & Solute carrier family 26, member 9 & 1.27 & 0.249 & -7.64 & $1.99 \times 10^{-7 a}$ \\
\hline SCGB3A1 & Secretoglobin, family $3 \mathrm{a}$, member 1 & 1.77 & 0.062 & -7.60 & $3.31 \times 10^{-7 a}$ \\
\hline
\end{tabular}

${ }^{\mathrm{a}} \mathrm{P}<0.001$. AD, lung adenocarcinoma; $\mathrm{SC}$, squamous cell carcinoma; $\mathrm{FC}$, fold-change.

A Upregulated Genes

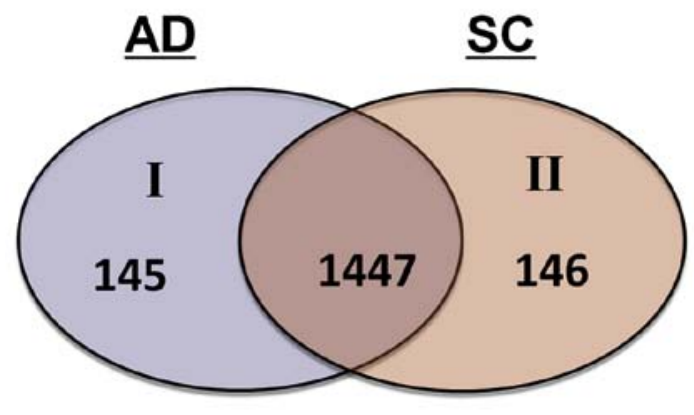

B

Downregulated Genes

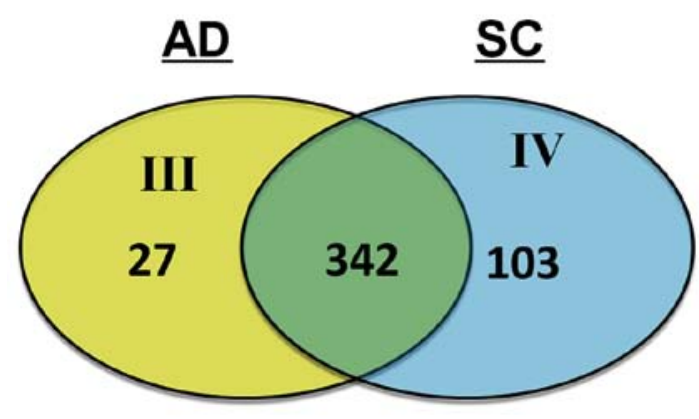

C Heatmap

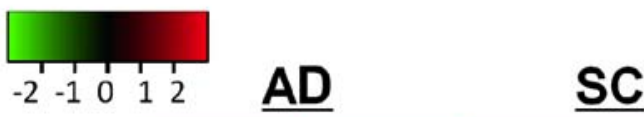

II

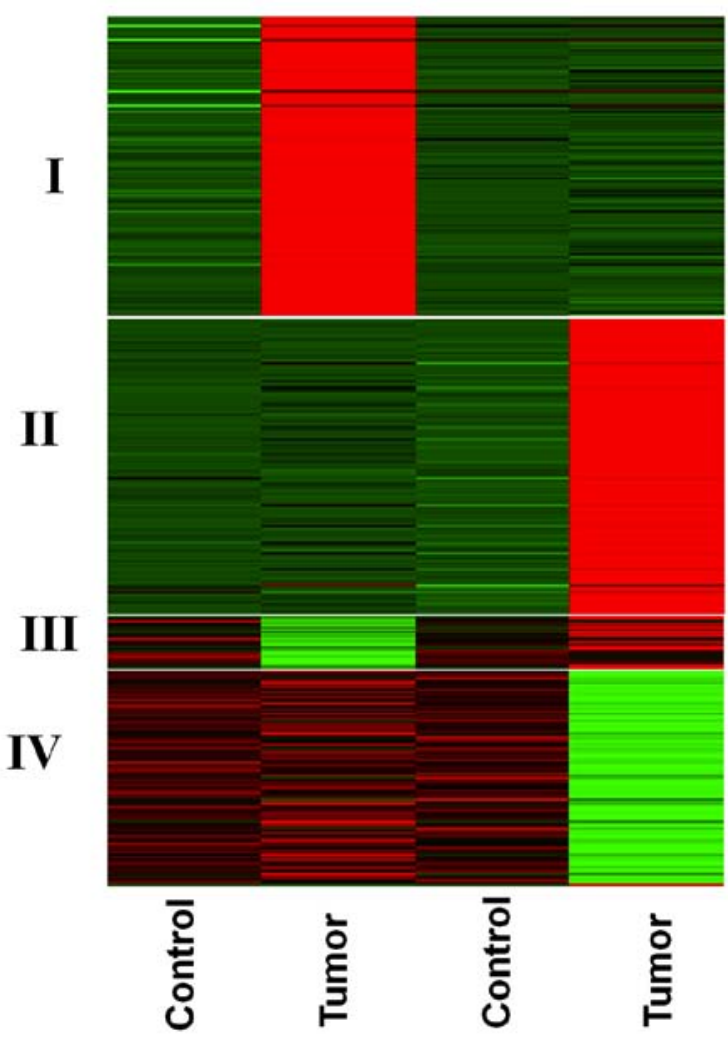

Figure 1. Differential gene expression in AD and SC. (A and B) Venn diagrams of the total number of genes commonly and uniquely (A) upregulated and (B) downregulated in the two cancer types. (C) Heat map demonstrating the clustering of unique gene sets of each subtype into four distinct groups. Gene expression magnitude is represented by the color ranging from high expression (red) to low expression (green). Groups I and II represent genes upregulated specifically in AD and SC, respectively while groups III and V represent genes downregulated specifically in AD and SC, respectively. AD, lung adenocarcinoma; SC, lung squamous cell carcinoma.

The canonical pathways 'LPS/IL-1 mediated inhibition of RXR function', 'xenobiotic metabolism signaling' and 'aryl hydrocarbon receptor signaling' were among those specifically dysregulated in SC. Peroxisome proliferator-activated receptor- $\gamma(P P A R G)$, which regulates 15 genes, $c$-Jun, which regulates 15 genes, and $R X R \alpha(R X R A)$, which regulates 14 genes, were among the upstream regulators of the differentially regulated genes (Table IV). 

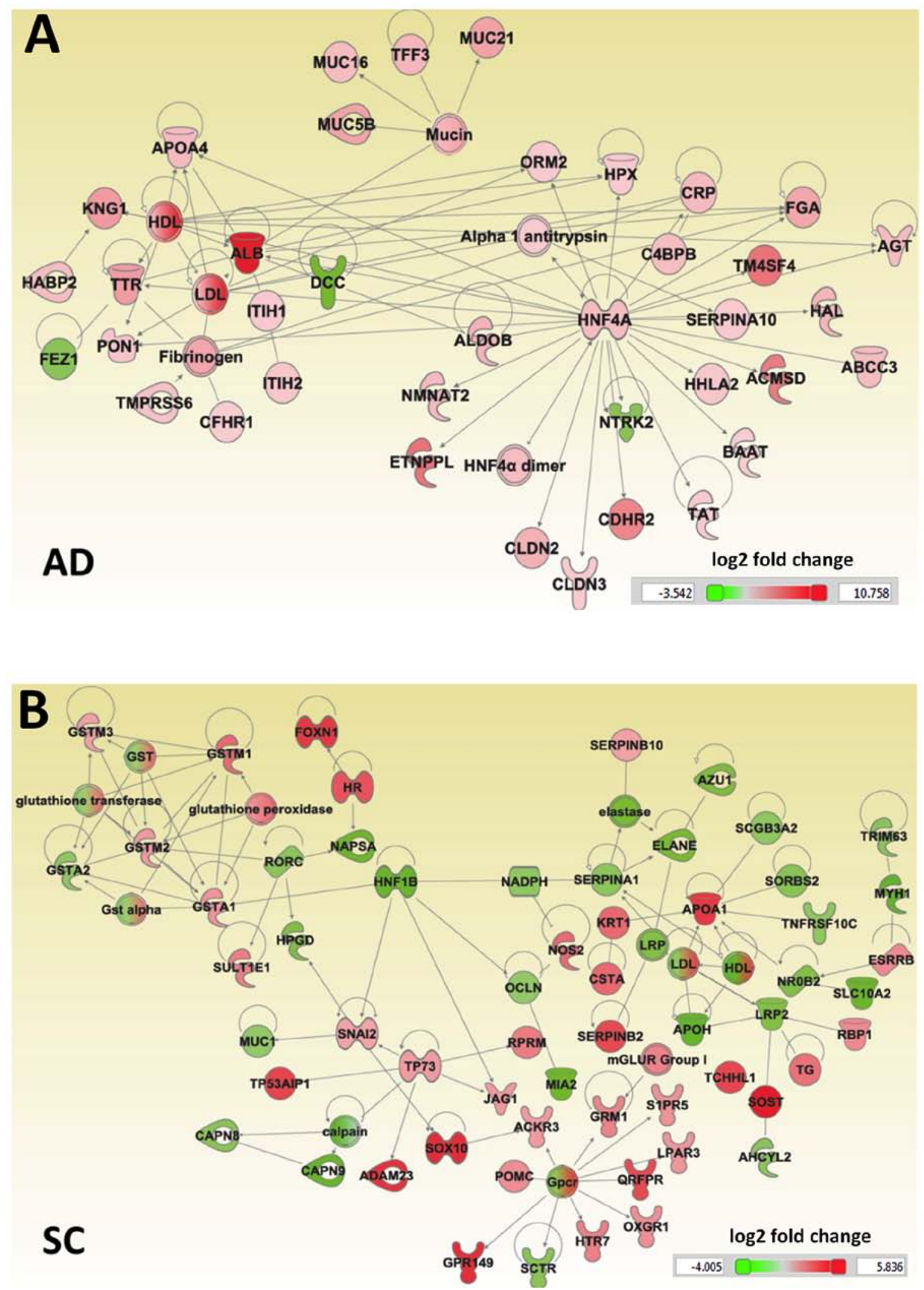

Figure 2. Interaction networks of genes uniquely altered in AD and SC. (A and B) Ingenuity Pathway Analysis tool was used to generate interaction networks using (A) AD- and (B) SC-specific genes. Each gene is represented as a node, and edges represent interactions between nodes. Red nodes indicate upregulated genes, and green nodes indicate downregulated genes. AD, lung adenocarcinoma; SC, lung squamous cell carcinoma.

\section{Discussion}

Lung carcinomas account for $>25 \%$ of cancer-associated mortalities worldwide, and the majority of primary lung cancers are NSCLC histological subtypes, including AD and SC (3). Personalized treatment for these cancers requires a complete and detailed understanding of the distinct molecular mechanisms that contribute to tumorigenesis, especially in 
Table III. Functional annotation terms of genes enriched in lung adenocarcinoma.

\begin{tabular}{|c|c|c|}
\hline Gene Ontology term & Count & P-value \\
\hline \multicolumn{3}{|l|}{ Molecular and cellular functions } \\
\hline Small molecule biochemistry & 50 & $3.0 \times 10^{-5}$ \\
\hline Molecular transport & 43 & $1.6 \times 10^{-5}$ \\
\hline Cell-to-cell signaling and interaction & 42 & $2.1 \times 10^{-5}$ \\
\hline Amino acid metabolism & 18 & $3.0 \times 10^{-5}$ \\
\hline Cellular growth and proliferation & 16 & $2.1 \times 10^{-5}$ \\
\hline \multicolumn{3}{|l|}{ Canonical pathways } \\
\hline FXR/RXR activation & 13 & $1.1 \times 10^{-11}$ \\
\hline LXR/RXR activation & 9 & $3.2 \times 10^{-7}$ \\
\hline Acute phase response signaling & 9 & $7.3 \times 10^{-6}$ \\
\hline eNOS signaling & 6 & $1.9 \times 10^{-3}$ \\
\hline Coagulation system & 3 & $2.2 \times 10^{-3}$ \\
\hline \multicolumn{3}{|l|}{ Upstream regulators } \\
\hline Hepatocyte nuclear factor $4-\alpha$ & 26 & $7.7 \times 10^{-3}$ \\
\hline Hepatocyte nuclear factor $1-\alpha$ & 22 & $2.6 \times 10^{-12}$ \\
\hline Transcription activator BRG1 & 14 & $2.0 \times 10^{-4}$ \\
\hline Forkhead Box protein A2 & 10 & $1.9 \times 10^{-6}$ \\
\hline $\begin{array}{l}\text { Peroxisome proliferator-activated } \\
\text { receptor } \alpha\end{array}$ & 10 & $2.1 \times 10^{-3}$ \\
\hline LIM/homeobox protein Lhx1 & 8 & $1.2 \times 10^{-6}$ \\
\hline Forkhead Box protein A1 & 8 & $1.8 \times 10^{-5}$ \\
\hline Bile acid receptor & 7 & $1.6 \times 10^{-4}$ \\
\hline PR domain zinc finger protein 1 & 7 & $1.6 \times 10^{-3}$ \\
\hline Myoblast determination protein 1 & 6 & $2.6 \times 10^{-3}$ \\
\hline $\begin{array}{l}\text { Mothers against decapentaplegic } \\
\text { homolog } 3\end{array}$ & 6 & $7.4 \times 10^{-3}$ \\
\hline
\end{tabular}

early stages when survival rates are $>90 \%$. In the present study, a total of 172 genes with differential expression (145 upregulated and 27 downregulated) specific to $\mathrm{AD}$, and another 249 genes (146 upregulated and 103 downregulated) specific to SC were identified.

The present study demonstrated that early-stage AD exhibited a 150-fold upregulation of the oncogene LIN28A, which is involved in cell cycle progression through the regulation of cyclin-dependent kinase 2 in lung, breast, ovarian, colon, liver and pancreatic cancer (22). In addition, LIN28 has been demonstrated to confer resistance to radiotherapy in lung carcinoma cell lines (23) and has been explored for its potential role in breast cancer therapy (24). The results of the present study revealed that the activity of this oncogene was unique to the AD subtype of NSCLC, whereas no significant changes in LIN28 expression levels were observed in SC. These results suggested that LIN28A may be a novel therapeutic target for AD. The palate, lung and nasal epithelium carcinoma-associated gene, which has a documented association with respiratory tumors with a glandular phenotype (25), was upregulated 38-fold in AD in the present study. Members of the mucin family of genes, mucin 21 cell surface-associated and mucin 5 b oligomeric mucus/gel-forming, were identified to be upregulated
Table IV. Functional annotation terms enriched in lung squamous cell carcinoma.

\begin{tabular}{|c|c|c|}
\hline Gene Ontology term & Count & P-value \\
\hline \multicolumn{3}{|l|}{ Molecular and cellular functions } \\
\hline Small molecule biochemistry & 58 & $7.9 \times 10^{-8}$ \\
\hline Lipid metabolism & 45 & $7.9 \times 10^{-8}$ \\
\hline Vitamin and mineral metabolism & 26 & $7.9 \times 10^{-8}$ \\
\hline Drug metabolism & 15 & $3.8 \times 10^{-6}$ \\
\hline Free radical scavenging & 10 & $1.1 \times 10^{-5}$ \\
\hline \multicolumn{3}{|l|}{ Canonical pathways } \\
\hline $\begin{array}{l}\text { LPS/IL- } 1 \text { mediated inhibition } \\
\text { of RXR function }\end{array}$ & 14 & $4.6 \times 10^{-8}$ \\
\hline Xenobiotic metabolism signaling & 12 & $3.5 \times 10^{-5}$ \\
\hline Aryl hydrocarbon receptor signaling & 10 & $1.6 \times 10^{-6}$ \\
\hline PXR/RXR activation & 6 & $5.8 \times 10^{-5}$ \\
\hline Glutathione-mediated detoxification & 5 & $5.0 \times 10^{-5}$ \\
\hline \multicolumn{3}{|l|}{ Upstream regulators } \\
\hline $\begin{array}{l}\text { Peroxisome proliferator-activated } \\
\text { receptor } \gamma\end{array}$ & 15 & $5.8 \times 10^{-5}$ \\
\hline Transcription factor AP-1 & 15 & $5.4 \times 10^{-5}$ \\
\hline Retinoic acid receptor RXR- $\alpha$ & 14 & $5.0 \times 10^{-7}$ \\
\hline Estrogen receptor $\beta$ & 13 & $7.2 \times 10^{-5}$ \\
\hline Tumor protein 63 & 13 & $1.4 \times 10^{-4}$ \\
\hline Retinoic acid receptor $\alpha$ & 12 & $8.9 \times 10^{-5}$ \\
\hline Histone deacetylase 1 & 11 & $5.0 \times 10^{-5}$ \\
\hline Homeobox protein Nkx-2.1 & 10 & $1.4 \times 10^{-5}$ \\
\hline Zinc finger protein GLI2 & 7 & $7.9 \times 10^{-5}$ \\
\hline LIM/homeobox protein Lhx1 & 7 & $9.0 \times 10^{-5}$ \\
\hline
\end{tabular}

15-fold in AD, and are likely to be involved in the excessive secretion of mucus by neoplastic cells in AD (26). Mucin peptides incorporated into liposomal vaccines are associated with extended survival times in patients with lung cancer (27). Downregulation of several tumor suppressor genes including SOSTDC1, ODAM, deleted in colorectal carcinoma, fasciculation and elongation proteins $\zeta 1$ and annexin A8 was observed in AD, but not in SC. These genes are associated with a variety of cancers, including lung, breast, colon and prostate cancer (28-31).

In the present study, early-stage SC exhibited specific upregulation of CTA family 45 members A1-4. Auto-antibodies against the genes of this family have been demonstrated to serve as biomarkers for NSCLC with low sensitivity and high specificity (32), and a RNAseq catalog of 90 cancer testis antigens were established by Djureinovic et al (33). The results of the present study also demonstrated that the expression of another member of the CTA family, X antigen family member 2, was downregulated in SC; this gene has previously been identified as a tumor suppressor in metastatic melanoma and Ewing sarcoma (34). In addition, SC exhibited downregulation of several tumor suppressor genes, including melanoma inhibitory activity 2 , which is involved in hepatocellular carcinoma (30), and secretoglobin family 3 a member 1 , which serves a role in testicular germ cell tumors $(35,36)$. 
In the present study, 'cellular function' and 'lipid metabolism' were associated with the genes dysregulated specifically in early-stage SC. Alterations in lipid metabolism have been previously implicated in human cancers, particularly oral squamous cell carcinoma, in which increased lipid metabolism is associated with invasiveness (37). Previous studies have reported that impaired lipid metabolism in NSCLC results in the loss of malignant potential (38-40). The results of the present study suggested that abnormal lipid metabolism may be specific to SC. AD exhibited significant upregulation of LIPF; however, no evidence of dysregulated lipid metabolism in $\mathrm{AD}$ was observed at a functional level. By contrast, $\mathrm{AD}$ exhibited alterations in 'molecular transport', 'cell-to-cell signaling and interaction' and 'amino acid metabolism'.

Only SC exhibited strong enrichment of the 'drug metabolism' cellular function in the present study. Previous studies have suggested that high activity levels of cytochrome P450 isotypes, particularly cytochrome P450 family 1 (CYPI) subfamily B member 1 (CYPIB1), serve a role in carcinogenesis and drug resistance in human cancers, including NSCLC, and may serve as therapeutic targets or prognostic indicators $(41,42)$. In addition, 5,7-dimethoxyflavone and resveratrol have been used to inhibit CYP1 family protein expression Hep G2 human hepatoma and MCF-10a non-tumorigenic human mammary epithelial cell lines, respectively $(43,44)$. The results of the present study revealed that the 'PXR/RXR', 'xenobiotic metabolism signaling', 'aryl hydrocarbon receptor signaling' and 'glutathione-mediated detoxification' canonical pathways were also altered in early-stage SC. Previous studies have demonstrated that PXR serves a role in xenobiotic metabolism in human malignancies, such as colon, breast and gynecologic cancers (45). The involvement of PXR in NSCLC has not been previously reported. The aryl hydrocarbon transcription factor is also involved in cytochrome metabolism and activates the CYP1B1, CYP1A1 and CYP1A2 isotypes (46). The results of the present study suggest that the dysregulation of genes associated with drug metabolism may be specific to SC, and that the role of these catabolic enzymes may be evident in early-stage cancer. These results also identify several potential mechanisms of chemotherapy resistance in SC.

The canonical pathways 'FXR/RXR activation' and 'LXR/RXR activation' were altered in early-stage $\mathrm{AD}$, and the $N R 1 H 4$ gene was identified as an upstream regulator of $\mathrm{AD}$ in the present study. Previous studies of $F X R / R X R$ in human cancers have demonstrated that it is activated in breast and esophageal cancers, but can be downregulated in hepatobiliary cancers (47-49). Loss of $L X R / R X R$ is involved in the growth and progression of prostatic carcinomas, and LXR agonists have emerged as a novel therapy for prostate cancer (50). The canonical pathways 'LPS/IL-1 mediated inhibition of RXR function' and 'PXR/RXR activation' were altered in SC in the present study. $P X R / R X R$ is involved in the metabolism of xenobiotics and has been demonstrated to be involved in multiple types of human cancer, including colon, breast and gynecological cancers (45). Previous studies have demonstrated the use of retinoid receptor expression as a prognostic indicator in stage I NSCLC, but the role of specific retinoid receptors has not been explored $(51,52)$. The involvement of $F X R / R X R, L X R / R X R$ and $P X R / R X R$ in NSCLC subtypes is a novel finding of the present study.

The results of the present study demonstrated that HNF4A and $H N F 1 A$ were upstream regulators of the genes specifically dysregulated in AD. A previous study has identified the use of $H N F 4 A$ as a biomarker for $\mathrm{AD}$, and another study identified $H N F 4 G$ to be involved in the AKT signaling pathway in lung cancer $(20,53)$. The present results suggest that $H N F$ may be an upstream driver of tumorigenesis. In addition, SMARCA4 was identified as another upstream regulator in AD. Upregulation of this gene in $\mathrm{AD}$ is associated with poor prognosis and a poor response to platinum-based chemotherapy $(54,55)$. Analysis of the upstream regulators in the present study also identified FOXA2 and FOXA1 as specific regulators of AD; the FOXA2 gene product has been demonstrated to prevent lung tumor growth and metastasis by preventing epithelial-mesenchymal transition (21).

In the present study PPARG, $c-J U N$ and RXRA were the most significant upstream regulators of the genes specifically differentially regulated in early-stage SC. The role of $P P A R G$ in lung cancer is unclear, although $P P A R G$ has been studied in the context of pulmonary fibrosis, where it was demonstrated to repress myofibroblast differentiation (56). However, upregulation of $P P A R G$ repressed tumor growth in pancreatic and colorectal cancer $(57,58)$, and $P P A R G$ inhibitors have been used to induce anti-estrogen susceptibility in mammary tumors (59). The role of the $c$-JUN regulator in NSCLC may be related to the dysregulation of retinoid signaling by the inhibition of $R X R A$, which is another upstream regulator of the genes altered in SC (60). Based on prior studies $(61,62), c-J U N$ may be activated and RXRA may be consequently inhibited in SC. Anti-tumor activity has been achieved through c-JUN protein inhibition using a bisphenazine anticancer drug (63). Several other upstream regulators were identified in the present study, such as estrogen receptor 2 and tumor protein p63, which have been previously demonstrated to serve roles in $\operatorname{NSCLC}(64,65)$.

The major limitation of the present study was the lack of experimental validation of the findings using in vivo or in vitro experiments. However, to minimize false positives, a very stringent cut-off was used to select the DEGs. In addition, the large sample set provided high statistical power to discover the differences with high confidence.

In conclusion, the present study revealed early-stage differences in the gene expression profiles of AD and SC. Unique sets of genes altered in each subtype were identified; for example, ALB, LIN28A, LIPF, TM4SF4, AGXT2L1 and $A C M S D$ genes were upregulated $>50$-fold in $\mathrm{AD}$, but were not significantly upregulated in SD. Similarly, $A M T N, A D H 7$, $S O S T$ and $C L D N 22$ were upregulated $>50$-fold in SC, but not in AD. Several CTA family genes were highly upregulated in $\mathrm{SC}$, but not in $\mathrm{AD}$, whereas several mucins were upregulated only in AD. In addition, 'lipid metabolism' and 'drug metabolism' pathways were associated with genes dysregulated specifically in SC, whereas 'molecular transport' and 'cellular growth and proliferation' were significantly enriched only in AD. The results of the present study provided gene expression alterations specific to each subtype, which may help to identify the molecular mechanisms underlying the pathogenesis of these subtypes. These findings also provide targets for future studies investigating novel diagnostic methods and personalized therapeutic approaches for AD and SC.

\section{Acknowledgements}

Not applicable. 


\section{Funding}

The present study was supported by the Institutional Start-Up Package to AS from the Medical College of Georgia at Augusta University, Augusta, GA, USA.

\section{Availability of data and materials}

The datasets analyzed for this study are available from The Cancer Genome Atlas (https://cancergenome.nih.gov).

\section{Authors' contributions}

NV, JY and AS wrote the manuscript and created the figures and tables. TJL and SKK performed data analysis. NV, JY, SS, AS and NP contributed to the data interpretation. All authors read and approved the final manuscript.

\section{Ethics approval and consent to participate}

This study utilizes a publicly available data set from TCGA (https://cancergenome.nih.gov/abouttcga) and was granted an exemption from requiring ethics approval by the Institutional Review Boards at Augusta University Augusta GA USA.

\section{Patient consent for publication}

Not applicable.

\section{Competing interests}

The authors declare that they have no competing interests.

\section{References}

1. Siegel RL, Miller KD and Jemal A: Cancer statistics, 2018. CA Cancer J Clin 68: 7-30, 2018.

2. Jemal A, Bray F, Center MM, Ferlay J, Ward E and Forman D: Global cancer statistics. CA Cancer J Clin 61: 69-90, 2011.

3. Torre LA, Siegel RL and Jemal A: Lung cancer statistics. Adv Exp Med Biol 893: 1-19, 2016.

4. Muralidharan-Chari V, Clancy JW, Sedgwick A and D'Souza-Schorey C: Microvesicles: Mediators of extracellular communication during cancer progression. J Cell Sci 123 1603-1611, 2010.

5. Choy B, Findeis-Hosey JJ, Li F, McMahon LA, Yang Q and $\mathrm{Xu} \mathrm{H}$ : High frequency of coexpression of maspin with $\mathrm{p} 63$ and p53 in squamous cell carcinoma but not in adenocarcinoma of the lung. Int J Clin Exp Pathol 6: 2542-2547, 2013.

6. Fukui T, Taniguchi T, Kawaguchi K, Fukumoto K, Nakamura S, Sakao Y and Yokoi K: Comparisons of the clinicopathological features and survival outcomes between lung cancer patients with adenocarcinoma and squamous cell carcinoma. Gen Thorac Cardiovasc Surg 63: 507-513, 2015.

7. Argon A, Nart D and Veral A: The value of cytokeratin 5/6, p63 and thyroid transcription factor-1 in adenocarcinoma, squamous cell carcinoma and non-small-cell lung cancer of the lung. Turk Patoloji Derg 31: 81-88, 2015.

8. Singhal S, Miller D, Ramalingam S and Sun SY: Gene expression profiling of non-small cell lung cancer. Lung Cancer 60: 313-324, 2008.

9. Shi WY, Liu KD, Xu SG, Zhang JT, Yu LL, Xu KQ and Zhang TF: Gene expression analysis of lung cancer. Eur Rev Med Pharmacol Sci 18: 217-228, 2014.

10. Lu C, Chen H, Shan $\mathrm{Z}$ and Yang L: Identification of differentially expressed genes between lung adenocarcinoma and lung squamous cell carcinoma by gene expression profiling. Mol Med Rep 14: 1483-1490, 2016.
11. Lacroix L, Commo F and Soria JC: Gene expression profiling of non-small-cell lung cancer. Expert Rev Mol Diagn 8: 167-178, 2008.

12. Grigoroiu M, Tagett R, Draghici S, Dima S, Nastase A, Florea R, Sorop A, Ilie V, Bacalbasa N, Tica V, et al: Gene-expression profiling in non-small cell lung cancer with invasion of mediastinal lymph nodes for prognosis evaluation. Cancer Genomics Proteomics 12: 231-242, 2015.

13. Yousef GM, Scorilas A, Nakamura T, Ellatif MA, Ponzone R, Biglia N, Maggiorotto F, Roagna R, Sismondi P and Diamandis EP: The prognostic value of the human kallikrein gene 9 (KLK9) in breast cancer. Breast Cancer Res Treat 78: 149-158, 2003.

14. Bahassi el $\mathrm{M}$ and Stambrook PJ: Next-generation sequencing technologies: Breaking the sound barrier of human genetics. Mutagenesis 29: 303-310, 2014.

15. Hagemann IS, Devarakonda S, Lockwood CM, Spencer DH, Guebert K, Bredemeyer AJ, Al-Kateb H, Nguyen TT, Duncavage EJ, Cottrell CE, et al: Clinical next-generation sequencing in patients with non-small cell lung cancer. Cancer 121: 631-639, 2015.

16. Xu X, Yang Y, Li H, Chen Z, Jiang G and Fei K: Assessment of the clinical application of detecting EGFR, KRAS, PIK3CA and BRAF mutations in patients with non-small cell lung cancer using next-generation sequencing. Scand J Clin Lab Invest 76: 386-392, 2016.

17. Benjamini Y and Hochberg Y: Controlling the false discovery rate-a practical and powerful approach to multiple testing. J R Stat Soc B 57: 289-300, 1995.

18. Wang T, Han P, He Y, Zhao C, Wang G, Yang W, Shan M, Zhu Y, Yang C, Weng M, et al: Lin28A enhances chemosensitivity of colon cancer cells to 5 -FU by promoting apoptosis in a let-7 independent manner. Tumour Biol 37: 7657-7665, 2016.

19. Shen H, Yang Y,Zhao L, Yuan J and Niu Y: Lin28A and androgen receptor expression in $\mathrm{ER}^{-} / \mathrm{Her} 2^{+}$breast cancer. Breast Cancer Res Treat 156: 135-147, 2016.

20. Sugano M, Nagasaka T, Sasaki E, Murakami Y, Hosoda W, Hida T, Mitsudomi T and Yatabe Y: HNF4 $\alpha$ as a marker for invasive mucinous adenocarcinoma of the lung. Am J Surg Pathol 37: 211-218, 2013.

21. Tang Y, Shu G, Yuan X, Jing N and Song J: FOXA2 functions as a suppressor of tumor metastasis by inhibition of epithelial-to-mesenchymal transition in human lung cancers. Cell Res 21: 316-326, 2011

22. Li N, Zhong X, Lin X, Guo J, Zou L, Tanyi JL, Shao Z, Liang S, Wang LP, Hwang WT, et al: Lin-28 homologue A (LIN28A) promotes cell cycle progression via regulation of cyclin-dependent kinase 2 (CDK2), cyclin D1 (CCND1), and cell division cycle 25 homolog A (CDC25A) expression in cancer. J Biol Chem 287: 17386-17397, 2012.

23. Oh JS, Kim JJ, Byun JY and Kim IA: Lin28-let7 modulates radiosensitivity of human cancer cells with activation of K-Ras. Int J Radiat Oncol Biol Phys 76: 5-8, 2010.

24. Xiong H, Zhao W, Wang J, Seifer BJ, Ye C, Chen Y, Jia Y, Chen C, Shen J, Wang L, et al: Oncogenic mechanisms of Lin28 in breast cancer: New functions and therapeutic opportunities. Oncotarget 8: 25721-25735, 2017.

25. Bingle L, Cross SS, High AS, Wallace WA, Devine DA, Havard S, Campos MA and Bingle CD: SPLUNC1 (PLUNC) is expressed in glandular tissues of the respiratory tract and in lung tumours with a glandular phenotype. J Pathol 205: 491-497, 2005.

26. Corfield AP: Mucins: A biologically relevant glycan barrier in mucosal protection. Biochim Biophys Acta 1850: 236-252, 2015.

27. Palmer M, Parker J, Modi S, Butts C, Smylie M, Meikle A, Kehoe M, MacLean G and Longenecker M: Phase I study of the BLP25 (MUC1 peptide) liposomal vaccine for active specific immunotherapy in stage IIIB/IV non-small-cell lung cancer. Clin Lung Cancer 3: 49-58, 2001

28. Liu L, Wu S, Yang Y, Cai J, Zhu X, Wu J, Li M and Guan H: SOSTDC1 is down-regulated in non-small cell lung cancer and contributes to cancer cell proliferation. Cell Biosci 6: 24, 2016.

29. Kestler DP, Foster JS, Bruker CT, Prenshaw JW, Kennel SJ, Wall JS, Weiss DT and Solomon A: ODAM expression inhibits human breast cancer tumorigenesis. Breast Cancer (Auckl) 5: 73-85, 2011.

30. Ishii H, Vecchione A, Murakumo Y, Baldassarre G, Numata S, Trapasso F, Alder H, Baffa R and Croce CM: FEZ1/LZTS1 gene at 8p22 suppresses cancer cell growth and regulates mitosis. Proc Natl Acad Sci USA 98: 10374-10379, 2001. 
31. Lee MJ, Yu GR, Yoo HJ, Kim JH, Yoon BI, Choi YK and Kim DG: ANXA8 down-regulation by EGF-FOXO4 signaling is involved in cell scattering and tumor metastasis of cholangiocarcinoma. Gastroenterology 137: 1138-1150, 1150.e1-e9, 2009.

32. Shan Q, Lou X, Xiao T, Zhang J, Sun H, Gao Y, Cheng S, Wu L, $\mathrm{Xu} \mathrm{N}$ and Liu S: A cancer/testis antigen microarray to screen autoantibody biomarkers of non-small cell lung cancer. Cancer Lett 328: 160-167, 2013.

33. Djureinovic D, Hallstrom BM, Horie M, Mattsson JSM, La Fleur L, Fagerberg L, Brunnström H, Lindskog C, Madjar K, Rahnenführer J, et al: Profiling cancer testis antigens in non-small-cell lung cancer. JCI Insight 1: e86837, 2016.

34. Zendman AJ, Van Kraats AA, Weidle UH, Ruiter DJ and Van Muijen GN: The XAGE family of cancer/testis-associated genes: Alignment and expression profile in normal tissues, melanoma lesions and Ewing's sarcoma. Int J Cancer 99: 361-369, 2002.

35. Hellerbrand C, Amann T, Schlegel J, Wild P, Bataille F, Spruss T, Hartmann A and Bosserhoff AK: The novel gene MIA2 acts as a tumour suppressor in hepatocellular carcinoma. Gut 57: 243-251, 2008.

36. Lind GE, Skotheim RI, Fraga MF, Abeler VM, Esteller M and Lothe RA: Novel epigenetically deregulated genes in testicular cancer include homeobox genes and SCGB3A1 (HIN-1). J Pathol 210: 441-449, 2006.

37. Sant'Anna-Silva ACB, Santos GC, Campos SPC, Oliveira Gomes AM, Perez-Valencia JA and Rumjanek FD: Metabolic profile of oral squamous carcinoma cell lines relies on a higher demand of lipid metabolism in metastatic cells. Front Oncol 8 : 13, 2018.

38. Long J, Zhang CJ, Zhu N, Du K, Yin YF, Tan X, Liao DF and Qin L: Lipid metabolism and carcinogenesis, cancer development. Am J Cancer Res 8: 778-791, 2018.

39. Luo X, Cheng C, Tan Z, Li N, Tang M, Yang L and Cao Y: Emerging roles of lipid metabolism in cancer metastasis. Mol Cancer 16: 76, 2017

40. Guo JY and White E: Autophagy is required for mitochondrial function, lipid metabolism, growth, and fate of KRAS (G12D)-driven lung tumors. Autophagy 9: 1636-1638, 2013.

41. Murray GI, Taylor MC, McFadyen MC, McKay JA, Greenlee WF Burke MD and Melvin WT: Tumor-specific expression of cytochrome P450 CYP1B1. Cancer Res 57: 3026-3031, 1997.

42. Su JM, Lin P, Wang CK and Chang H: Overexpression of cytochrome P450 1B1 in advanced non-small cell lung cancer: A potential therapeutic target. Anticancer Res 29: 509-515, 2009.

43. Chen ZH, Hurh YJ, Na HK, Kim JH, Chun YJ, Kim DH, Kang KS Cho MH and Surh YJ: Resveratrol inhibits TCDD-induced expression of CYP1A1 and CYP1B1 and catechol estrogen-mediated oxidative DNA damage in cultured human mammary epithelial cells. Carcinogenesis 25: 2005-2013, 2004

44. Wen X, Walle UK and Walle T: 5,7-Dimethoxyflavone downregulates CYP1A1 expression and benzo[a]pyrene-induced DNA binding in Hep G2 cells. Carcinogenesis 26: 803-809, 2005.

45. Qiao E, Ji M, Wu J, Ma R, Zhang X, He Y, Zha Q, Song X, Zhu LW and Tang J: Expression of the PXR gene in various types of cancer and drug resistance. Oncol Lett 5: 1093-1100, 2013.

46. Xue P, Fu J and Zhou Y: The aryl hydrocarbon receptor and tumor immunity. Front Immunol 9: 286, 2018.

47. Swales KE, Korbonits M, Carpenter R, Walsh DT, Warner TD and Bishop-Bailey D: The farnesoid X receptor is expressed in breast cancer and regulates apoptosis and aromatase expression. Cancer Res 66: 10120-10126, 2006.

48. Yang F, Huang X, Yi T, Yen Y, Moore DD and Huang W: Spontaneous development of liver tumors in the absence of the bile acid receptor farnesoid X receptor. Cancer Res 67: 863-867, 2007.

49. Guan B, Li H, Yang Z, Hoque A and Xu X: Inhibition of farnesoid $\mathrm{X}$ receptor controls esophageal cancer cell growth in vitro and in nude mouse xenografts. Cancer 119: 1321-1329, 2013.

50. Fukuchi J, Kokontis JM, Hiipakka RA, Chuu CP and Liao S: Antiproliferative effect of liver $\mathrm{X}$ receptor agonists on $\mathrm{LNCaP}$ human prostate cancer cells. Cancer Res 64: 7686-7689, 2004.
51. Khuri FR, Lotan R, Kemp BL, Lippman SM, Wu H, Feng L, Lee JJ, Cooksley CS, Parr B, Chang E, et al: Retinoic acid receptor-beta as a prognostic indicator in stage I non-small-cell lung cancer. J Clin Oncol 18: 2798-2804, 2000

52. Chang YS, Chung JH, Shin DH, Chung KY, Kim YS, Chang J, Kim SK and Kim SK: Retinoic acid receptor-beta expression in stage I non-small cell lung cancer and adjacent normal appearing bronchial epithelium. Yonsei Med J 45: 435-442, 2004.

53. Wang J,Zhang J, Xu L, Zheng Y,Ling D and Yang Z: Expression of HNF4G and its potential functions in lung cancer. Oncotarget 9 : 18018-18028, 2017.

54. Bell EH, Chakraborty AR, Mo X, Liu Z, Shilo K, Kirste S, Stegmaier P, McNulty M, Karachaliou N, Rosell R, et al: SMARCA4/BRG1 is a novel prognostic biomarker predictive of cisplatin-based chemotherapy outcomes in resected non-small cell lung cancer. Clin Cancer Res 22: 2396-2404, 2016.

55. Guerrero-Martinez JA and Reyes JC: High expression of SMARCA4 or SMARCA2 is frequently associated with an opposite prognosis in cancer. Sci Rep 8: 2043, 2018.

56. Kulkarni AA, Thatcher TH, Olsen KC, Maggirwar SB Phipps RP and Sime PJ: PPAR- $\gamma$ ligands repress TGF $\beta$-induced myofibroblast differentiation by targeting the PI3K/Akt pathway: Implications for therapy of fibrosis. PLoS One 6: e15909, 2011.

57. Elnemr A, Ohta T, Iwata K, Ninomia I, Fushida S, Nishimura G, Kitagawa H, Kayahara M, Yamamoto M, Terada T and Miwa K: PPARgamma ligand (thiazolidinedione) induces growth arrest and differentiation markers of human pancreatic cancer cells. Int J Oncol 17: 1157-1164, 2000.

58. Ogino S, Shima K, Baba Y, Nosho K, Irahara N, Kure S, Chen L, Toyoda S, Kirkner GJ, Wang YL, et al: Colorectal cancer expression of peroxisome proliferator-activated receptor gamma (PPARG, PPARgamma) is associated with good prognosis. Gastroenterology 136: 1242-1250, 2009.

59. Yuan H, Kopelovich L, Yin Y, Lu J and Glazer RI: Drug-targeted inhibition of peroxisome proliferator-activated receptor-gamma enhances the chemopreventive effect of anti-estrogen therapy. Oncotarget 3: 345-356, 2012.

60. Srinivas H, Juroske DM, Kalyankrishna S, Cody DD, Price RE, Xu XC, Narayanan R, Weigel NL and Kurie JM: c-Jun N-terminal kinase contributes to aberrant retinoid signaling in lung cancer cells by phosphorylating and inducing proteasomal degradation of retinoic acid receptor alpha. Mol Cell Biol 25: 1054-1069, 2005.

61. Szabo E, Riffe ME, Steinberg SM, Birrer MJ and Linnoila RI: Altered cJUN expression: An early event in human lung carcinogenesis. Cancer Res 56: 305-315, 1996.

62. Xu XC, Sozzi G, Lee JS, Lee JJ, Pastorino U, Pilotti S, Kurie JM, Hong WK and Lotan R: Suppression of retinoic acid receptor beta in non-small-cell lung cancer in vivo: Implications for lung cancer development. J Natl Cancer Inst 89: 624-629, 1997.

63. Dai J, Punchihewa C, Mistry P, Ooi AT and Yang D: Novel DNA bis-intercalation by MLN944, a potent clinical bisphenazine anticancer drug. J Biol Chem 279: 46096-46103, 2004.

64. Marquez-Garban DC, Chen HW, Fishbein MC, Goodglick L and Pietras RJ: Estrogen receptor signaling pathways in human non-small cell lung cancer. Steroids 72: 135-143, 2007.

65. Borczuk AC, Gorenstein L, Walter KL, Assaad AA, Wang L and Powell CA: Non-small-cell lung cancer molecular signatures recapitulate lung developmental pathways. Am J Pathol 163: 1949-1960, 2003

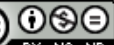

This work is licensed under a Creative Commons Attribution-NonCommercial-NoDerivatives 4.0 International (CC BY-NC-ND 4.0) License. 